\title{
Hidden factors that influence success in the optics workforce
}

\author{
Anne E. Leak, Zackary Santos, Erik Reiter, and Benjamin M. Zwickl \\ School of Physics and Astronomy, Rochester Institute of Technology, \\ 84 Lomb Memorial Drive, Rochester, New York 14623, USA \\ Kelly Norris Martin \\ School of Communication, Rochester Institute of Technology, \\ 92 Lomb Memorial Drive, New York 14623, USA
}

(Received 10 August 2017; published 12 June 2018)

\begin{abstract}
To prepare physics students for future careers, educators need to understand the skills and other factors necessary for entry and success on the job. Often these insights are based on CEOs, HR personnel, and managers, who provide broad perspectives regarding successful attributes of new hires. However, such insights are often more general and disconnected from specific jobs than insights gained from entry-level employees who recently transitioned from school to work. Using in-depth descriptive summaries and thematic analysis from interviews with six recently hired technicians and engineers in the field of optics, we explored factors that influenced their entry and success on the job. Six themes arose: documentation, computational skills, specialized learning, question asking, tinkering skills, and navigating cultural differences. We discuss the implications of these themes in both their value to employees as well as integration into the physics curriculum.

DOI: $10.1103 /$ PhysRevPhysEducRes.14.010136
\end{abstract}

\section{INTRODUCTION}

In order to prepare physics students for a diverse range of career paths, educators need to recognize possible paths and provide opportunities aligned with what makes employees successful [1]. Students taking physics courses can pursue a variety of careers. First, physics courses serve both physics majors and nonphysics majors. College students also take physics in a variety of programs including 4-year colleges and universities as well as community colleges. Even for physics majors at 4-year universities, contrary to popular student and often faculty beliefs, graduate school is not their only option. Of the over 7430 physics bachelors degrees awarded in 2013-14 and surveyed a year later by the American Institute of Physics (AIP), $41 \%$ entered the workforce and did not attend a graduate or professional school [2]. In fact, over half of physics bachelor's graduates entering the workforce obtained jobs in the private sector [3]. The most common jobs for physics bachelor's recipients were in the fields of engineering or computer science [4].

Research does not typically address best practices for physics education research (PER) at community colleges or

Published by the American Physical Society under the terms of the Creative Commons Attribution 4.0 International license. Further distribution of this work must maintain attribution to the author(s) and the published article's title, journal citation, and DOI. for transfer students (other than a few studies, such as Refs. [5,6]). Additionally, community colleges serve both associates degree recipients who enter the workforce directly and those who transfer to four-year colleges or universities. Community colleges tend to be more diverse when compared to most 4-year colleges and universities, so learning from community college students or graduates may help us advance equity in physics. In community colleges, physics programs tend to serve higher rates of students from lower income families, first generation college students, and traditionally underserved minorities. Research that accounts for the perspectives of technicians who do not typically have four-year degrees, in addition to scientists and engineers, is more inclusive of multiple pathways into STEM.

While research has identified the skills, both technical and nontechnical, STEM graduates find valuable on the job, these are rarely reported in depth (with the exception of Lottero-Purdue and Brickhouse [7] who interviewed 10 employees about the high-school science they use at a company that designs and manufactures technical products). Most workplace studies tend to be aggregate reports of general skill lists provided by experts (e.g., Ref. [8]) or broad surveys of graduates (e.g., Refs. [4,9]) with limited connection to everyday experiences and scientific practices. Though limited in their depth and connection to context, these studies are essential for obtaining an overall view of the skills physics students may need upon graduation. For instance, Mulvey and Pold [4] identified the knowledge and 
skills regularly used by 2011 and 2012 physics bachelor's recipients employed in the private sector. These included solving technical problems, working on a team, technical writing, design and development, use of specialized equipment, and programming, among others [4].

With many physics bachelor's recipients entering industry, it is also worth considering attributes experts considered important for future engineers. According to the NRC report, The Engineer of 2020 [8], these attributes included strong analytical skills, practical ingenuity (e.g., planning, combining, and adapting), the ability to identify problems and find solutions, creativity, and good communication. Other key competencies included understanding the principles of business and management, high ethical standards, and a strong sense of professionalism. Because of the fast pace and constant changing nature of technology, it is also essential that engineers possess dynamism, agility, resilience, and flexibility as well as be lifelong learners. While the NRC report justifies the need for each of the attributes mentioned above, the committee of experts identified such needs broadly in order to look across multiple fields and generalize to prepare multiple students for a diverse range of future careers [8].

Surveys with graduates have also provided useful perspectives on the value of specific undergraduate learning and competencies for recent hires. Passow [9] used surveys of engineering graduates to identify and determine the relative importance of ABET competencies for professional practice. This study indicated that the most important professional competencies over seven survey administrations from 1999 to 2005 consistently included teamwork, communication, data analysis, and problem solving. Yet, what does solving technical problems look like on the job? Why is being able to work on a team a valuable skill and what are the difficulties new hires face in doing so? Answering these questions is important for developing physics curricula that will adequately prepare students for their future.

While engineering and other broad STEM career studies are valuable, we also need qualitative discipline-specific research of post-graduate perspectives just like we need qualitative discipline-based education research for understanding how students learn in STEM disciplines. Unfortunately, prior research tends to focus on large studies which produce varied estimates of STEM jobs in the United States, from 5.4 to 26 million. Moreover, these often group very different jobs into the single category of STEM [10]. In these labor market studies, blue-collar jobs requiring STEM knowledge are also commonly overlooked and these workers are not included in estimates or in identifying the necessary competencies of the sector [10]. The inclusion of these jobs will also likely improve the diversity of socioeconomics, races, and genders represented in PER. In addition to identifying the need for clearly defining what a STEM job is and the factors necessary for success in these jobs, our findings highlight the need for a more in-depth analysis of the scientific practices and skills necessary for success in specific STEM fields.

Martin and colleagues [11] recognized the need for rich and contextual data that interviews provide in identifying issues related to preparation for professional practice not identified in engineering education literature. They conducted a qualitative analysis of interviews with graduates to examine the graduates' perceptions of their preparation for work in industry. Their work not only confirmed important attributes determined from experts and prior research surveying graduates, but added depth and connection to contexts of the work itself. For example, their study determined the strong connections between technical and nontechnical skills, factors affecting communication skills (e.g., practice, confidence, technical knowledge, and personality), and that graduates felt underprepared for taking leadership roles in teams among other findings. Such research opens new avenues for exploring skills and knowledge that graduates rely on in their jobs by connecting these to their in-depth use and context. This allows educators to better plan meaningful learning opportunities as well as highlights issues that can be further explored by researchers.

With these advantages in mind, this study seeks to explore careers in optics and photonics via in-depth interviews with participants. To do so, we pose the following research question: Based on their workplace experiences, what factors (e.g., competencies, cultural fit, prior experiences) influence recently hired optics employees' entry and success on the job? In addition to addressing this question, we discuss our approach in relation to other PER methods to identify the strengths and limitations of descriptive thematic analysis of in-depth interviews with recently hired employees.

\section{METHODS}

Using a semistructured interview protocol, we interviewed new hires that worked in optics and photonics companies in the northeastern United States between 2015 and 2016. While we collected 30 interviews, including new hires and direct managers, this study focuses on the experiences of six new hires (Table I). Using a purposeful internal sampling method [12], we selected these six as representative of the range of backgrounds and experiences across the larger sample and to include different genders, ethnicities, educational background, and job type. Only 2 out of the 6 participants were female since we wanted to include their perspectives, but it was difficult to recruit female participants since there are so few in the field of optics and photonics. In purposefully sampling participants, we attempted to represent a larger sample while also ensuring that we include diverse perspectives. To protect our participants, we do not provide specific details on race and ethnicity. To protect each company's proprietary information and clients, we provide only a broad context of the 
TABLE I. Participants.

\begin{tabular}{lcccc}
\hline \hline Name $^{\mathrm{a}}$ & Position & Education & Gender & ELL $^{\mathrm{c}}$ \\
\hline Ashley & Engineer & Master's & Female & No \\
Otis & Engineer & Bachelor's & Male & No \\
Jerrold & Technician & High School & Male & No \\
Jim & Technician & Some CC & Male & Yes \\
Kristen & Technician & High School & Female & Yes \\
Alan & Engineer & Master's & Male & No \\
\hline \hline
\end{tabular}

${ }^{\mathrm{a}}$ Names given are pseudonyms to protect the identity of participants.

${ }^{\mathrm{b}} \mathrm{CC}$ : Community college.

${ }^{\mathrm{c}}$ ELL: English language learner.

focus, applications, and procedures for each. Focusing on six interviews, each approximately $1 \mathrm{hr}$ in length, provided us with $6 \mathrm{hr}$ and $17 \mathrm{~min}$ of data and enabled us to do an indepth analysis of each individual's experiences.

Interviews were transcribed and coded using NVIVO qualitative analysis software through a multistage coding process. First, interview transcripts were structurally coded by discipline-specific content, including physics or optics, math, and communication. Using emergent and process coding methods, each discipline was coded for specific skills discussed [13]. Additionally, the physics or optics subset of the data was coded for references to learning or training of physics and optics skills. We chose, from our data, six representative interviews to look at closely for the factors that influence their entry and success in their positions.

After the six key interviews were selected, we used indepth descriptive analysis for each and detailed their subjective experiences. Descriptive analysis, while most often used in observational research, can be used as a unit of inquiry in interviews to reflect both the participant's experiences or perspectives and the questions and biases of the researcher [14]. Similarly, portrait writing has been used in ethnographic education research as a way to document effective schools and for producing a full contextually embedded picture of an event or person [15]. In science education research, such methods have been used to study equity and access of underrepresented minorities in science (e.g., Refs. [16,17]). Using a combination of descriptive context statements and ethnographic portrait writing techniques [12], we created what we refer to as descriptive summaries for each participant. Each descriptive summary reflects the interviewee's work experiences from their perspectives as well as the underlying interests guiding our research to include how the participant learned skillseither machine work, software, or both-through their respective education or on the job training. We also include how participant's job duties affected what they considered important, any future plans, and the how cultural factors influenced their work. The descriptive summaries are presented in this paper as both ethnographic portrait data for work experiences in and of themselves, and as a rich context to better interpret emergent themes.
After completing the descriptive processes and summaries for each interview, we used thematic analysis to look within and across participants' described experiences in optics and photonics [13]. In PER, thematic analysis of qualitative interviews has been successful for documenting and understanding the experiences of underrepresented minorities. For example, Rosa and Mensah used such methods to examine the experiences and obstacles faced by six black women physicists [18]. While our six participants do not all identify as underrepresented minorities (although three do), the voices of new hires are not often heard from in physics education research. Our study explores these voices and brings to light some typically hidden factors that are necessary for success in physicsintensive careers. Thematic analysis allowed us to identify the meaning behind codes to understand these factors and how they influence success in the optics workplace. Through this process, six main themes emerged and became the central focus for our paper.

\section{FINDINGS}

In this paper, we first present descriptive summaries of six interviews in Sec. III A. These stories summarize the detailed experiences of new hires and provide a context for understanding what factors influence recently hired optics employees' entry and success on the job. In Sec. III B, our findings are then examined by theme to look at emergent trends across the experiences described in Sec. III A. While this paper focuses on findings from the perspectives of new hires, we also critically examine the strengths and limitations of methods of descriptive analysis for use in PER. This is explained in Sec. III C. Our findings suggest that success in optics is influenced by a multitude of hidden factors, factors that are rarely explicit goals of physics courses.

\section{A. Interview summaries}

Our selected interviews cover various job titles and positions in a company's hierarchy as well as educational backgrounds. This diversity of experiences and backgrounds provides a strong representation of the optics 
workforce in western New York. Each descriptive summary below provides a portrait of an employee that is valuable for understanding different possible physics-related careers and as a rich context for understanding factors that are necessary to enter and succeed in such positions.

\section{Ashley: Lens designer and visual communicator}

Ashley works at a company that makes lenses for projection systems in a variety of industries. These range from mass produced and sometimes modular parts to completely customized lenses. The company is spread across three continents. In her role, Ashley works frequently with senior designers and interacts directly with her clients.

In her current position, Ashley designs lenses for projectors. To complete daily tasks, Ashley uses multiple software packages-most often Zemax, Inventor, and Excel. Zemax is used to design the lenses, Inventor to draw them, and Excel to do arithmetic such as geometry and angle calculations. Ashley did not come to her current job knowing Zemax and needed to teach herself. It was about six months before she felt comfortable with the software.

One main goal of Ashley's work, aside from interfacing with customers, is to design what she calls a "Master Lens." This lens would be average across many specifications with supplementary lenses added to change the focal length or angle. If successful, producing custom lenses would become more economical.

To help design her lenses, Ashley often relies on archives, pulling up old lens designs as a starting point. This strategy has its challenges, though. The company is growing and older designs were made when the company was smaller and there was only one designer. Since he worked on his own, only he needed to understand his documentation. Because of this, he often omitted measurements or key information Ashley needs to have a workable design.

Typically, Ashley's customers know specifications like where an image will be, how large it will be, and the basics of what the produced image will need to look like. Ashley then takes this information and turns it into a lens that fits within the design space. Communication problems occur when customers do not speak the language of optics. One example of this is when using the word aperture. Since "aperture" can mean either the $F$ number or the clear aperture, she needs to interpret their meaning and then translate her answer into the same vocabulary the customers are using. These sorts of communication issues can arise internally as well. In her work, Ashley also needs to communicate with system engineers who deal with the entire projector system and not just the lenses. Typically, they do not know the specifics of lens design. Ashley described the problems trying to communicate with people without dumbing down what she is saying so much that it does not mean anything, but also without overwhelming them with nonsense. To help with communication barriers, Ashley uses a clear plastic Christmas ornament. She split it in half so she could draw on the hemispheres with white board markers. This allows her to draw in three dimensions directly rather than try to recreate a three-dimensional image in two dimensions for her customers or co-workers. This visual communication tool makes it much easier to show and explain projection to people who may not be as proficient in the field.

In her position, Ashley works with many other engineers, all of whom are men. She feels like she gets treated differently as a women. An example of this is when the "guys" qualify their talk by adding, "you can't say that, there is a girl here." This phrase was tossed around at happy hours a few times before Ashley spoke up about it. This was not the only way that Ashley felt left out in a workplace, and not always due to her gender. At her previous job, Ashley was the only person in her position under the age of 45 . She felt considerably younger than the rest of her co-workers making her more of an outsider. Communication is very important for Ashley's work, but in the same way she often feels left out of social events in her male-dominated workplace; she also feels left out of workrelated communication. Her co-workers often meet informally during lunchtime runs. While she tries to fill them in on progress she made on a problem, they often write off her contributions by saying, "we talked about that already on the run."

\section{Kristen: Visual inspector and social illuminator}

Kristen works at a company focused on designing and manufacturing optics. The company is unique in that it uses optics made from plastic rather than traditional glass based on its accordances as a more durable, lightweight, and affordable material. Additionally, this allows for more affordable techniques such as injection molding that can be employed to reduce production costs. Kristen works in a testing and measurement position and communicates directly with a partner in a similar role, technicians, and company managers.

In her position, Kristen performs visual inspection of optical pieces. She volunteered for this new position after working on the factory floor making the parts that she now inspects. Kristen works with a partner to evaluate a variety of parts, from medical applications to airplanes.

Most of Kristen's inspections are conducted to prevent contamination of parts. In this work, patience and speed are very important. She has thousands of parts to get through in a single week. When a part is deemed not good enough to ship out, Kristen takes a picture of it and scraps it. Her inspections are typically done with a loupe, or small magnifying glass. In addition to checking for contamination, Kristen also ensures that the shape of the optic is correct and within the standards needed by the customer. 
Kristen also measures the reflectivity of the optic with a laser and occasionally clips pieces for shipping.

Kristen had no previous optics experience prior to her position. She has learned all she needs to know about optics from her partner and supervisor. Kristen also knows what to look for in each part by reading daily production sheets. She does this everyday, regardless of whether she has worked with the part before, in order to prevent mistakes. Some parts require more than thirteen steps to compete an inspection and these are often difficult to memorize. In Kristen's job, documentation is vital. At the end of every day, she takes inventory of the parts that were scrapped as well as the total number of parts she inspected.

Kristen feels very comfortable with the writing aspect of her job. Occasionally, she also needs to talk with people one on one via telephone. Kristen learned English as a second language and is not as comfortable with speaking as she is with reading and writing.

Since moving from the manufacturing floor to her office upstairs as an inspector, Kristen has been working more closely with managers, rather than the just people who make the parts. Kristen feels that she and her partner have been the subject of racist attitudes by other co-workers on the floor and sees herself as somewhat of an outsider from them. On the other hand, Kristen sees that the managers do not always know what goes on in the factory. She refers to the managers as the people upstairs and talks about the upstairs-downstairs divide.

\section{Jim: Machine operator and inquisitive learner}

Jim's place of employment specializes in large glass blanks that other companies purchase in order to make their own lenses and other products. Making glass blanks requires the glass to be incredibly flat and uniform. Furthermore, specializing in blanks allows the company to serve and connect with many industries including automotive, lighting, lasers, glass art, aerospace, government, scientific applications, and telecommunications. Jim works directly with co-workers on the manufacturing floor and has a few senior mentors.

Jim works with the glass and a variety of tools directly, grinding sheets to specified thicknesses. Grinding glass down without breaking it and maintaining a smooth surface requires substantial knowledge of how machines and materials work. Blocking the glass, the process of holding it in place with stationary blocks, adds lots of stress to the lens. As it heats from the grinding, it can expand and cause even more warping and stress. Warping is an issue that Jim must consider since the optics he produces are supposed to be flat. Jim's work also requires measurement and calculations. Grinding is done with specialized sandpaper that is measured in grits the same way regular sandpaper is. Jim also needs to be aware of temperatures, but he does not do the calculations by hand. He uses an understanding of temperature to get the correct water to oil percentage in order to maintain a workable temperature then cool the part once grinding is complete, without causing warping. For most of these calculations, Jim uses a calculator.

For Jim, English is a second language and in his job, communication is vital. During shift changes, Jim needs to understand what the person before him finished and where he needs to start. This communication takes place during a $1 \mathrm{hr}$ overlap in shifts. Jim has learned much of his communication strategies, and his knowledge of optics on the job. He mostly relies on asking questions to gather information that helps him perform various tasks. Asking questions is essential when an order comes through that does not make sense. He asks for explanations of visual diagrams and design tolerances to better understand the order.

In his position, Jim feels that he is the youngest and the rest of his co-workers are much older. He thinks this has been beneficial for him getting work since several older workers are looking to retire soon. Jim is currently attending optics courses at a local community college to learn more and hopes to move up in the optics field.

\section{Jerrold: Glass polisher and data interpreter}

Jerrold works in a company that specializes in flat optics. The company makes a variety of products including equipment to test products and devices using optics including beam splitters, prisms, mirrors, and filters. These products are used by a variety of industries such as telecommunication and astronomy. In his position, Jerrold interacts with the other workers on the manufacturing floor, in a specialized product development role, and with his direct managers.

Jerrold works mainly in polishing, but also has experience with beveling, grinding, lapping, metrology, and buckling. To do this, Jerrold employs a variety of tools and techniques. His company is currently restructuring and will likely keep him in polishing as a specialist, rather than having him do multiple jobs. Jerrold is also currently pursuing a bachelor's degree in engineering while working part-time.

In high school, Jerrold learned to use hands-on tools such as a spirometer from his dad who was a machinist. In school, Jerrold also learned about thin and thick lenses, aberrations, and the manufacturing process. He is currently in college while working as a technician for an optics company. His company provides formal optics training and assists people in pursuing higher education.

In his work, Jerrold has learned to be careful with his measurements and be able to interpret them accurately. As an example, when using a spirometer the measurement can be either negative or positive, the magnitude of which is not important for this example. Instead, the negative or positive measurement relates to the curvature of the lens. These measurements need to be done accurately and interpreted correctly in order for a correct piece to be produced. 
Jerrold also needs to know how to identify and fix a mistake when the solution is not part of a predetermined run time and pressure. Temperature is also a factor, but Jerrold does not have to deal with it directly. Calculators, pens, and paper are located around the shop to help Jerrold do calculations as needed. These calculations usually pertain to the length of time on a machine that a part needs before it is done.

Jerrold feels that school projects have helped him learn to keep logs at work since he had to write down everything he did in the projects. Jerrold frequently asks questions to people in upper management who he finds very helpful. Employees are taught that if they have a question, they can just ask. Jerrold described communication in his job as having three parts. Part one is the need to communicate with your replacement and help them pick up where you left off during shift changes. Part two is documenting everything that you do, including keeping track of parts that have come through, how many were scrapped, how many failed, and reasons why. These logs serve as a communication tool between machine operators and managers. Part three of communication is having fun and joking around on the job. Keeping it less serious is important so everyone can come in and leave happy.

\section{Alan: Engineering consultant and hands-on experience educator}

Alan works at a large company with close to 50000 employees in North America, Europe, and Asia. The company has a footing in material science fields with a focus on glass and ceramics. Their products have major applications in green technology, pharmaceuticals, communications, and optics. Alan is an optical engineer with various expertises and as such works as an engineering consultant for multiple company sites. He is not a manager, but instead interacts directly with scientists and engineers across many different divisions in the company as well as educators and students outside of the company.

Alan works as an engineer for an the optics portion of the company as well as teaches classes at a local community college. Teaching allows Alan to translate what he values as an engineer to preparing and recruiting students. In his company, it is rare for technicians to work up into managerial positions without further education, which is highly valued.

Alan's work relies on Excel and Word for documentation. Other tasks involve coding in MatLab, Light Tools, and Code V. In the classes he teaches, Alan focuses on measurements and measurement errors so that students learn what causes them and how to evaluate the quality of data.

Alan's passion for teaching is shown throughout the interview and he elaborates more on those experiences and his students' perspectives than his own engineering work.

\section{Otis: Vacuum systems engineer and team negotiator}

Otis works for a small company, with less than 50 employees, that focuses on organic light emitting diode (OLED) technology. They provide lighting solutions for a broad spectrum of industries such as interior design, health, and transportation. The lighting fixtures produced by the company are thin and energy efficient. These properties allow them to be installed in near limitless locations. Otis himself oversees a small team.

Otis has a graduate degree in electrical engineering and currently works as a systems engineer in a department that focuses on a vacuum system crystal growth process. He started this job as a co-op where he wrote enough code to make himself indispensable. The main software he has developed tracks products through the facility at all points in production and allows managers to know what tests and inspections were performed and how well the product did. He has since moved into a systems engineering role.

Otis feels that his graduate work prepared him for knowing how to learn and provided a basic understanding of programming and engineering. Otis integrates formulas into software that he develops, rarely doing the math out by hand. For example, the company vibrates a crystal in a vacuum chamber and by measuring the changes in frequencies, they can determine growth rates. This uses a long standard formula, but Otis has not had to use it since initially integrating it into his software.

As part of his work, Otis leads a small team of people and needs to be competent at communicating his thoughts and needs to the team. One of the bigger challenges Otis faces is how to get things moving and done as a leader, while still maintaining friendships. Otis feels that his ability to lead and work well with others came from crossdisciplinary projects during his time as an undergraduate. He prefers face-to-face communication since it allows him to see and interpret mannerisms. Most of his communication is internal and culminates in a weekly meeting. At these meetings, he and his colleagues talk about where they are and where they want to be at the end of the week. Otis also takes daily notes and adds them to a shared drive so anyone in the company can read them and feel included in the work. When Otis runs into problems, he asks others for help.

\section{B. Factors that influence entry and success in optics}

From the interviews with new hires and their descriptive summaries, six themes arose that explain the factors influencing success in the optics and photonics workplace (see Fig. 1). These themes describe how knowledge is acquired in a workplace setting as well as the soft skills and cultural factors that play a key role in an employee's daily tasks. 


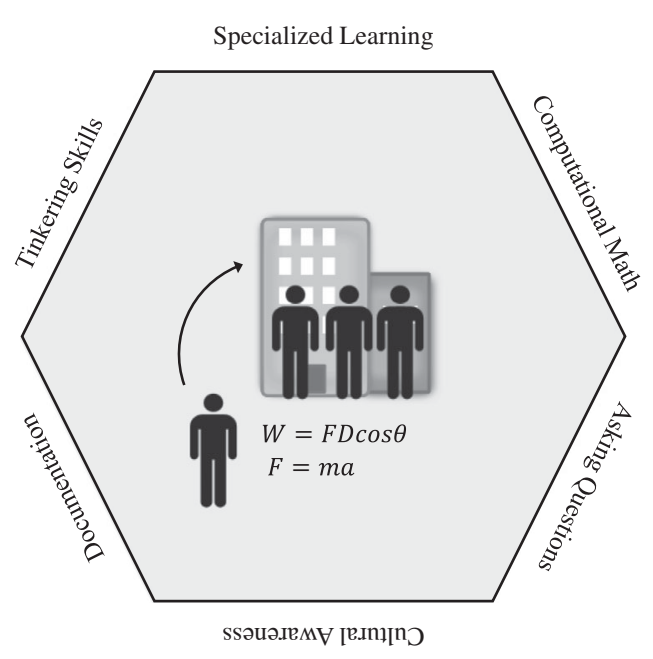

FIG. 1. Factors that influence entry and success in the optics and photonics workforce.

\section{Specialized learning on the job}

Specialized learning takes many forms across the field of optics as employees master specific skills to complete tasks and succeed in their positions. For our interviewees, Ashley taught herself the software she needed to know. After six months, she felt confident that she could use the software effectively to complete her daily tasks. Even though she learned this new software on the job, she used other engineering programs for design like Code $\mathrm{V}$ as an undergraduate. Since she had a deep understanding of Code V, Ashley knew what she needed to learn to be able to use the new software, Zemax, effectively. In recounting this learning process, Ashley explains that,

When I started... I was using CODE5 which I learned to use in the school, so I felt pretty good about that. I felt like I knew how to use the software, but I had to learn how to use it for a specific problem. Then when I came here we use Zemax instead of CODE5, and so I had no idea how to use it. I was like, "I bet it can do this because the other program can do this but I have no idea how." And I spent my first week or so with a giant manual going through and doing tutorials, and then after like a month... I started to feel more confident... and wasn't always going to the manual or asking other people. There's still features I don't know how to use, but I feel pretty confident with it now.

Alan talked about learning software in his interview as well. He finds it more valuable to learn one program in depth, rather than get a baseline familiarity in several different programs. As Alan explained, knowing the capabilities of engineering programs makes it so that in a new program, you know what it is you are looking for and what you can feasibly do.

Software is not the only thing learned on the job in the optics industry, sometimes it is the optics itself. Otis obtained a degree in electrical engineering and now works with optics in vacuum systems. His optics education came entirely from his work. His undergraduate degree gave him a strong background in programming which he uses everyday, while his theory-driven courses taught him how to learn. In other words, learning anything at all gave him the insight into what he needs to learn and how to learn it. In another case, Kristen started as a waitress and went to high school in another country. She had no prior optics knowledge, yet now has specialized skills inspecting optics parts, making sure they are up to standard, largely from onthe-job learning.

\section{Computational math and number sense}

Our findings show that math in the optics industry is rarely done by hand. Between powerful tools ranging from calculators and Excel to specialized software, math with pencil and paper was not a workplace norm.

In Otis's work, he was required to use his math understanding to work a process backwards with the desired end result being a model that can calculate the growth rate of a crystal. To do this, he measured the vibrational frequency of the crystal then did a couple of calculations to get its growth rate. This type of calculation can be valuable to a company when trying to estimate how long it will take to get a product to the customer. Yet, Otis does not need to look at the formula he uses directly for over a year. Instead, he puts the measurements into a program he made. The program then provides him the rate of growth the company needs. In this way, Otis was able to complete his work without referring to the original formulas or the constants involved.

In other cases, number sense is the aspect of math that is most critical on the job. For some companies, like Alan's, it is the ability to know when a measurement makes sense that really matters. In fact, Alan focused a large part of his own teaching on this skill. He wants students to recognize if a measurement they took is good or bad, and then take it a step further to ask why it is bad. How can I make it good? What could have gone wrong that is preventing me from getting the result I expected? What did I even expect to see from this type of measurement? As he explains,

...the other thing I teach a lot is about understanding about measurement uncertainty in measurement error, because for a couple of reasons. Number one is that you have to understand how good your measurement is, and how good the data are; and if the data are not-you can very easily interpret data incorrectly if you've got a noise level that's larger than what you're looking at. And the other thing is that when you start thinking about what's causing the uncertainty, it allows you to make a better setup. If the uncertainty is due to the alignment of this lens with this lens and they're not squared up, well, when you go to set it up, you're going to think about that and go, "I better figure out-" making setups-optical 
setups or any kind of mechanical set up-is all about figuring out how to get things precisely aligned.

Alan emphasizes the use of uncertainty, not in reporting a measurement, but how to use that in order to evaluate an experimental setup and improve on it. This is not dissimilar from Jerrold. Jerrold uses number sense as a way of knowing what it means when a measurement of concavity is made and it comes back positive or negative. Critically evaluating measurements and interpreting results is crucial to his work.

\section{Asking meaningful questions}

Self-teaching does not happen on its own without supporting skills. In order to learn, employees need to identify what they need to know, and who and what to ask. Asking questions is a valuable skill that leads to further learning.

Every interviewee, in one way or another, recounted a time where they needed to ask questions to supervisors or other experts. Ashley needed to ask questions about Zemax while she was learning to use it. When Otis needed to pick up optics knowledge for his new job, he asked people with optics Ph.D.s for help. Kristen directly asked her manager and her partner questions about how the pieces she inspects are made and work. Jim asked about diagrams that guide his work when a portion looks incorrect. Jerrold discussed how his company is a place where, "if you want to know something, just ask." By asking questions, expertise can be transferred between employees. This is an important aspect of industry work with numerous advantages. Jim noticed a difference in his learning when he changed from night shifts to morning shifts. In the morning shifts, there were more people for him to watch, ask questions, and learn from, as he reflects,

I used to work from 4:00 to 8:00, for four hours, and I didn't see anybody. But then this summer-I was still learning and there wasn't anybody there to help me out, so it was one of the reasons [my friend] here one summer told me I could come here during days from 8:00 to 12:00... Yeah, and that was when I got to know the people more and learn from them, watching them.

Questions are not only limited to obtaining goal-oriented facts and solutions. Both of the interviewees who work with machines used questions as a means to understand where employees working before them had left off when they came in or when a part comes in that does not quite make sense. Without proficiency in asking questions, the floor would be inefficient during shift changes since workers coming in would not know where to begin. As Jerrold explains, employers would rather employees ask questions and teach them about the job than waste time having them figure everything out on their own. He recalls how his question asking habit has changed since he started his job.
I definitely took it slow because I did not want to drop any parts, that's important. But you learn to be very careful in the job... you also learn to ask more questions than you've done previously. If you don't understand something, you ask it. You don't try to figure it out on your own because you don't want to mess around with company funding.

We can see that Jerrold is not fearful of asking for help from supervisors, and that his workplace encourages question asking. Being good at asking questions plays a substantial role in work flow for groups and individuals. A baseline of knowledge is needed in order to formulate these questions and we have seen employers training to this baseline and then encouraging question asking to fill in the gaps. Everyone is liable to forget information while explaining what was done in an entire day's work and miscommunication from lack of questioning could cost a company production time [19].

\section{Navigating cultural differences between the employee and workplace norms}

Cultural differences manifested themselves in many ways in the optics work environment. For Otis, this was seen when he became the leader of a small group. His group members were unhappy with him as their superior since they wanted someone to talk to who knew the optics and engineering side better than the efficiency and budgeting side that were Otis' strengths. They did not feel that he was educated enough on their work, or old enough, to tell them how to do it. Being friends with a few of his group members was particularly challenging since he was additionally concerned with the possibility of making his friends into enemies by acting as their superior.

Other interviews also highlighted issues of fitting in at the workplace. This was the case for Ashley in her role as the youngest and the only girl as well as for Jim and Jerrold in their roles as the youngest employees in their companies.

Kristen describes another cultural factor related to both hierarchy and race as she accounts,

It's just one supervisor that we don't feel comfortable, but I don't know why. She's [from a Caribbean island], so she's from outside too, so we feel like why? Why? It's just about the attitude. It's everything about the attitude because we have a meeting once in a week. That's one of the things that they always talk about. Don't bring problems from home.

Identifying as an immigrant and person of color herself, Kristen was attuned to racial and social conflicts in her workplace. Kristen also talked about the cultural difficulties she faced at work speaking a first language other than English, which Jim also experienced. Both Kristen and Jim's background is described broadly in Table I. 
As part of a company, workers will need to work with others who know more than they do and are most often able to use such people as resources; however, working with someone with different backgrounds and areas of expertise can create communication obstacles. In Ashley's job, she needs to meet with customers and figure out how the technology she is developing should function or assess the reasons why it might not function as expected. She developed strategies for communicating visually by designing a three-dimensional object she could draw on.

A lot of it's just being able to picture things in $3 D$ in your head... when we do planetarium kind of stuff where you're projecting a dome... that part's really hard for basically everyone. My latest trick is I bought this giant plastic Christmas ornament on Amazon, and it splits into two, so I have these two see through plastic hemispheres, and so you can actually draw on it with white-board marker and be like, "Here's what the outline should look like." And then you can actually turn it in your hand and show it to someone as opposed to trying to draw $3 D$ in $2 D$.

This clear plastic Christmas ornament facilitated better discussions about projectors by allowing her to draw her ideas and share them with others.

Whether they experienced explicit discrimination based on race, gender, age, or simply had to navigate differences in backgrounds, employees commonly faced challenges fitting in and communicating with others in the workplace. Factors for working through differences between the employee themselves and the norms of their workplace had a substantial impact on their ability to enter and succeed in their careers.

\section{Pervasiveness of documentation}

Keeping track of work progress, in a way that is understandable and useful for co-workers, is vital for keeping companies running smoothly. Otis created a program that collects and organizes information that individuals document. His program can collect and analyze data so his company is better prepared to determine how long a product will take to run through the production cycle and provide better, more accurate quotes to clients. In addition to this communication tool that Otis developed, his company also takes notes on what they do each day and uploads these to a shared drive. This allows others to access notes, solutions to problems, and stay in the loop on progress across multiple company divisions.

Documentation is also used by individuals to keep track of progress over time, as Jerrold explains,

So running down it's like okay this part has ran for 40 minutes, that's one cycle. Okay we flipped it so we draw an arrow down and then another 40 minutes and so on. Writing all that stuff down. Writing what specs are at, at the correct moment. What's failing, what's passing-stuff like that.

Ashley documents her design process so she can go back and use it later as a starting point for new designs. A written record of what happens in a company is useful from design through production. Kristen, Jim, and Jerrold all recounted how much time they spend each shift documenting their work cycle. Kristen uses an inventory sheet and Jerrold uses production $\operatorname{logs}$ to do this. Alan, in his dual role as industry mentor and community college instructor, focuses heavily on preparing people's writing skills since workers will be documenting everything they are doing and need strong skills to do so.

Most documentation skills were developed prior to entering the workforce. Employees learned this in high school or higher education. Lab notebooks were seen as good practice for documentation skills. Both Alan and Jerrold mention using lab notebooks to practice writing down everything they do and ensuring that their writing is clear and direct enough so that others could use them as well. Ashley talks about what happens when documentation is not done well.

Yeah, because I was trying to find out information about an old design and I found an old drawing, and I was like, 'There's no useful information on this.' And I was talking to a stack of people and they said, 'That's because when [the previous designer] drew this [he] was the only designer,' so he got what he wanted.

As Ashley explains in the example above, documentation is used to communicate between people and across time. Where one person documents something only for themselves in the moment, the document does not serve as a communicative tool. Documentation is essential for keeping track of work flow, recording solutions to problems, and training new hires. It is also used as a means of communicating between different workers who work different shifts. Documentation in industry is a group effort, rather than an individual practice.

\section{Valuing tinkering skills across roles}

For multiple roles within optics companies, it is important to know how to use simple hand tools and understand production methods. Alan explains this when he says that knowing how to use a hand tool, regardless of your position, can make your job much easier. Sometimes all you may need is a simple hole drilled, but when you send in a work order it can take a week to get done and get back to you. If you just do it yourself, right when you need it, the process is significantly faster, as Alan says,

...if you know how to use a lathe and a milling machine... that takes you big time up another notch, 
if the company you're with will allow you to use that stuff. I can't tell you how many times you need a hole drilled in a different spot. And if you've got the ability to do that-you don't have to have that skill as an engineer, and if you don't have it you'll wait three days.

For those whose job it is to design a product, rather than make it, knowing what goes into the manufacturing process and taking that into consideration provides a valuable perspective on design quality and function. Kristen used to make the parts that she now inspects. Since she already knew how to handle and make parts, she was quickly able to learn what to look for upon inspection allowing her to make a successful transition into the new position.

Tinkering skills are valuable on the job both to understand different roles in a company and to be able to solve quick problems that require hands on tools independently. Regardless of job type, new employees found substantial value in tinkering skills and these helped them both solve problems themselves and understand the work of others in their company.

\section{Reflections on method of in-depth employee interviews for PER}

The physics education research community has had a limited voice in conversations related to workforce development, though many physics degree holders pursue STEM careers. In fact, a search for the word "workforce" within Physical Review Physics Education Research and its predecessor, Physical Review Special Topics Physics Education Research, since its inception in 2005 shows only a few articles on career decisions and the experiences of students in physics programs. Moreover, research on problem solving, mathematization within physics, physics identity, and other key areas of research have rarely utilized professional workplaces (either academic or private sector industry) to better understand learning physics, the disciplinary culture of physics, and expert practices in physics. Instead, the leaders in workforce issues tend to be business associations, economic development agencies, professional societies, community colleges, local governments, and proactive companies (e.g., Refs. [20-24]). However, most of this work tends to rely on quantitative survey methods and labor market statistics, neglecting the wide range of alternative social science research methods that may be appropriate for understanding aspects of physics in the workplace.

In our study, we conducted in-depth qualitative interviews and used descriptive summaries and a thematic approach for analysis. We were able to ask questions similar to survey methods for workforce research, such as what skills are valued and what strengths helped employees attain their job. These types of research questions are most often included in quantitative survey research. Using the methods found most often in interview data collection and analysis, we were able to go deeper into those skills and find out why employees think these things, attain descriptions of daily work processes, see the environment they are working in, and clarify on the spot if need be. Using semistructured, in-depth interviews allowed us to go beyond survey questions and have a conversation about the skills used every day in the workforce. While it was more time intensive, the data we collected using this method are rich and can be used as an alternative or complement to findings from traditional surveys that address similar questions.

In this study we focused on employees, and not merely their employers. One limitation of employer-focused studies is that managers have a less detailed awareness of day to day workplace practices of their supervisees. We are able to circumvent that by interviewing employees directly. Since we were able to go into companies and see the workplace from their perspective, we obtained a deeper understanding of daily workplace practices. The type of research questions we are able to answer in this study are what skills new hires need in their everyday work, while if we were to interview managers we would get a broad view of everyone. Only talking to new hires would be limiting, though, in that we might fail to understand how employee skills fit into the broader goals of the company or evaluate specific needs across the company. Yet, speaking with new hires expanded our understanding of the ways science is used everyday for particular cases. If future PER recognizes the value in such approaches, as a community we can explore multiple possible career paths for physicists in order to better understand where our physics students need to go after they graduate and help them get there.

\section{CONCLUSIONS}

Physics students have multiple pathways after graduating, yet advice is fairly generic for supporting them for their future careers. Our study provides a detailed exploration of some of the factors that make employees successful in physics-intensive careers in the optics industry. The factors we discuss include specialized learning on the job, computational math and number sense, asking meaningful questions, navigating cultural differences and workplace norms, and valuing tinkering. The stories about each employee serve to contextualize and personalize these factors and share commonly unheard voices with the physics education community. Furthermore, our study highlights the ways in which in-depth qualitative interviews with employees can be used in PER. Such methods can help to look beyond students' application of their learning within a course or from one course to the next toward what students can do after graduating.

There are hidden factors that enable people to enter and succeed in optics and photonics careers, yet these are typically not explicit values or expectations of the traditional physics major. Recent research and reports have 
identified some of these broadly and emphasized a need for holistic learning, soft skills, 21st century skills, and educating a T-shaped student [1,25-28]. Our research connects these broad recommendations to physics by providing rich accounts demonstrating their relevance in physics-intensive careers with implications for physics students specifically. For example, our research emphasizes the need for students to learn lab work that teaches handson tinkering skills for their equipment and documentation in a way that others (besides their professor) can access their notes [29]. Since learning these factors can help new hires succeed in physics-intensive careers, we should more explicitly value them in undergraduate physics.

One way to apply the findings of this research is to integrate additional opportunities for learning workplace relevant skills into the physics curriculum. To incorporate opportunities for learning number sense, for instance, a course could include specific opportunities for students to interpret and assess their findings and uncertainties with a goal of evaluating multiple approaches for measurement or considering limitations based on cost and time. For encouraging students to ask meaningful questions, a course could include an assignment that allows students to develop meaningful questions as a graded expectation, rather than an assumption of misunderstanding or the need for clarification. This could be done by positioning a lab activity in a real-world situation with a [mock] client that students must ask questions to in order to determine their best course of action for the lab. Additionally, teamwork could be structured and teams formed so that each student brings different expertise and diversity to a goal-oriented project [30]. Workers will often have different expertise and work in diverse teams, so that when combined they can find solutions they would not normally be able to. Instead of assuming students are adaptable and work effectively with others in team situations, providing support for interdisciplinary collaboration and team problem solving will better prepare students for the workplace [31].

In addition to integrating novel opportunities for learning typically hidden factors for success into physics curricula, students could be encouraged to connect their learning from other courses, research or work experiences, maker spaces, and clubs with their physics education [11,32]. Professional development or career preparation workshops can help students find relevance in their activities outside of physics coursework and determine what additional learning opportunities would help them develop skills related to their specific career interests. Internships and co-ops also provide opportunities for students to experience and reflect on the factors that will influence their success in future careers. Undergraduate research, similarly, requires students to develop depth and specialization of skills while relying on tinkering skills, authentic communication, and self-directed learning.

In the workplace and in academia, an individual's ability to fit in and succeed can be influenced by differences in culture and workplace norms, and more seriously by explicit racism, ageism, and sexism. Our findings indicate that class differences also lead to conflict in the workplace, where socioeconomic background can impact what level of degree employees obtain and some workplaces have limited mobility for technicians who tend to enter with a high school diploma or associates degree. While we feel that responsibility for changing norms should be placed on the workplace, all students can learn strategies for navigating and changing cultures to be more inclusive and respectful of others in order to create inclusive work environments. As our findings emphasize, traditionally under-represented, or more accurately underserved, students in physics need even more preparation for how to navigate difficult workplace cultures if they are to succeed in physics-intensive careers (though we would rather this is not the case). Such experiences, rather than being viewed as supplemental for a degree in physics, should in fact be valued as an essential aspect of learning.

In PER, our study provides valuable insight into the work of new hires in the local optics industry. Further research could apply similar methods to understand other career paths physics majors might take in other locations. Using in-depth descriptive analysis of qualitative interviews allowed us to see hidden factors that we otherwise would not have looked for or discovered using other methods, though this method is limited by scope and can be time intensive. Additionally, we were limited by how much detail we could provide on the demographic and background information for our participants in order to protect their identities, clients with whom they work, and the proprietary needs of their companies. Further research is needed to represent a diverse range of voices from employees in rich workplace settings. This will ensure that decisions for what students should learn and how they should learn are informed by what students may experience after leaving the classroom, rather than simply what will help them move from one physics course to the next. Despite limitations, physics faculty should be aware of the factors that influence success in the workplace as these can differ from the learning emphasized in traditional physics courses. Future research can add new voices and help broaden our understanding of who can do physics and what physics can look like in our students' future careers.

\section{ACKNOWLEDGMENTS}

This work is supported by NSF DGE-1432578 and REU-1359262. 
[1] R. W. Bybee and B. Fuchs, Preparing the 21st century workforce: A new reform in science and technology education, J. Res. Sci. Teach. 43, 349 (2006).

[2] J. Pold and P. Mulvey, Physics Bachelors: One Year After Degree, Tech. Rep. (American Institute of Physics, New York, 2016).

[3] S. Nicholson and P. J. Mulvey, Roster of Physics Department With Enrollment and Degree Data (2008).

[4] P. Mulvey and J. Pold, Physics Bachelor's Initial Employment, Technical Report (American Institute of Physics, New York, 2015).

[5] N. Lasry, E. Mazur, and J. Watkins, Peer instruction: From Harvard to the two-year college, Am. J. Phys. 76, 1066 (2008).

[6] R. A. Shotwell, Integrated instruction: Lasers across the curriculum in an associate's degree program, J. Laser Appl. 8, 217 (1996).

[7] P. Lottero-Perdue and N. Brickhouse, Learning on the job: The acquisition of scientific competence, Sci. Educ. 86, 756 (2002).

[8] National Academy of Engineering, The Engineer of 2020: Visions of Engineering in the New Century (National Academies Press, Washington, DC, 2004), DOI: 10.17226/ 10999.

[9] H. Passow, Which ABET competencies do engineering graduates find most important in their work?, J. Eng. Educ. 101, 95 (2012).

[10] A. Oleson, M. Hora, and R. J. Benbow, What is a STEM job? How different interpretations of the acronym result in a disparate labor market projections, Technical Report (Center on Education and Work, University of Wisconsin, Madison, Wisconsin, 2014), Viewpoint Paper \#1.

[11] R. Martin, B. Maytham, J. Case, and D. Fraser, Engineering graduates perceptions of how well they were prepared for work in industry, Eur. J. Eng. Educ. 30, 167 (2005).

[12] R. C. Bogdan and S. K. Biklen, Qualitative Research for Education: An Introduction to Theory and Methods (Pearson, New York, 2007).

[13] J. Saldaña, The Coding Manual for Qualitative Researchers, 2nd ed. (Sage, Los Angeles, 2013).

[14] J. Spradley, Participant Observation (Holt, Rinehart and Winston, New York, 1980), ISBN:0-03-044501-9.

[15] T. K. Chapman, Interrogating classroom relationships and events: Using portraiture and critical race theory in education research, Educ. Res. 36, 156 (2007).

[16] A. Johnson, J. Brown, H. Carlone, and A. K. Cuevas, Authoring identity amidst the treacherous terrain of science: A multiracial feminist examination of the journeys of three women of color in science, J. Res. Sci. Teach. 48, 339 (2011).

[17] E. Tan, A. C. Barton, H. Kang, and T. O’Neill, Desiring a career in STEM-related fields: How middle school girls articulate and negotiate identities-in-practice in science: Middle School Girls' Narrated And Embodied IdentitiesIn-Practice, J. Res. Sci. Teach. 50, 1143 (2013).
[18] K. Rosa and F. M. Mensah, Educational pathways of Black women physicists: Stories of experiencing and overcoming obstacles in life, Phys. Rev. Phys. Educ. Res. 12, 020113 (2016).

[19] N. Miyake and D. Norman, To ask a question, one must know what is not known, Center for Human Information Processing, University of California, San Diego, Report No. 7802, 1978.

[20] BLM: Higher Ed Critical to Growing MI s Economy, Technical Report, Business Leaders for Michigan, 2015.

[21] Workforce Solutions Group, State of St. Louis Workforce Report 2014, Workforce Solutions Group, STLCC, Technical Report.

[22] Associates Hart Research, Falling Short? College Learning and Career Success: Selected Findings from Online Surveys of Employers and College Students Conducted on Behalf of the Association of American Colleges \& Universities, 1-13 (2015).

[23] M. J. Handel, Skills mismatch in the labor market, Annu. Rev. Sociol. 29, 135 (2003).

[24] American Society for Training and Development, Bridging the skills gap, Technical Report 9781562868710 (2006).

[25] P. Harris, Help wanted: "T-Shaped" skills to meet 21st century needs, Training and Development 63, 42 (2009), https:/www.td.org/magazines/td-magazine/help-wanted-tshaped-skills-to-meet-21st-century-needs.

[26] P. Heron and L. McNeil, Phys 21: Preparing Physics Students for 21st-Century Careers, Technical Report (American Physical Society, 2016), ISBN: 978-09982529-9-5.

[27] L. Woolf and D. Arion, Phys21: Supplement to Phys21: Preparing Physics Students for 21st-Century Careers, Technical Report (American Physical Society, 2016).

[28] National Research Council, Education for Life and Work: Developing Transferable Knowledge and Skills in the 21 st Century, edited by J. W. Pellegrino and M. L. Hilton (The National Academies Press, Washington, DC, 2012).

[29] J. T. Stanley and H. J. Lewandowski, Lab notebooks as scientific communication: Investigating development from undergraduate courses to graduate research, Phys. Rev. Phys. Educ. Res. 12, 020129 (2016).

[30] M. L. Loughry, M. W. Ohland, and D. D. Moore, Development of a theory-based assessment of team member effectiveness, Educ. Psychol. Meas. 67, 505 (2007).

[31] A. Kedrowicz, Negotiating comfort in difference: making the case for interdisciplinary collaboration, in Proceedings of the 2004 American Society for Engineering Education Annual Conference \& Exposition (American Society for Engineering Education, Salt Lake City, UT, 2004), pp. 9.940.1-9.940.10.

[32] A.-b. Hunter, S. L. Laursen, and E. Seymour, Becoming a scientist: The role of undergraduate research in students' cognitive, personal, and professional development, Sci. Educ. 91, 36 (2007). 